\title{
Depletion of circulating blood NOS3 increases severity of myocardial infarction and left ventricular dysfunction
}

\author{
Marc W. Merx - Simone Gorressen - Annette M. van de Sandt • \\ Miriam M. Cortese-Krott · Jan Ohlig • Manuel Stern • Tienush Rassaf • \\ Axel Gödecke • Mark T. Gladwin • Malte Kelm
}

Received: 26 June 2013/Revised: 25 November 2013/ Accepted: 6 December 2013/Published online: 18 December 2013

(C) The Author(s) 2013. This article is published with open access at Springerlink.com

\begin{abstract}
Nitric oxide (NO) derived from endothelial NO synthase (NOS3) plays a central role in myocardial ischemia/ reperfusion (I/R)-injury. Subsets of circulating blood cells, including red blood cells (RBCs), carry a NOS3 and contribute to blood pressure regulation and $\mathrm{RBC}$ nitrite/nitrate formation. We hypothesized that the circulating blood born NOS3 also modulates the severity of myocardial infarction in disease models. We cross-transplanted bone marrow in wild-type and $\mathrm{NOS}^{-1-}$ mice with wild-type mice, producing chimeras expressing NOS3 only in vascular endothelium $(\mathrm{BC}-/ \mathrm{EC}+)$ or in both blood cells and vascular endothelium $(\mathrm{BC}+/ \mathrm{EC}+)$. After 60-min closed-chest coronary occlusion followed by $24 \mathrm{~h}$ reperfusion, cardiac function, infarct size
\end{abstract}

M.W. Merx and S. Gorressen equally contributed.

Electronic supplementary material The online version of this article (doi:10.1007/s00395-013-0398-1) contains supplementary material, which is available to authorized users.

M. W. Merx $(\bowtie) \cdot$ S. Gorressen · A. M. van de Sandt .

M. M. Cortese-Krott · J. Ohlig · M. Stern · T. Rassaf · M. Kelm

Division of Cardiology, Pneumology and Angiology,

Department of Medicine, University Hospital Düsseldorf,

Moorenstrasse 5, 40225 Düsseldorf, Germany

e-mail: marc.merx@med.uni-duesseldorf.de

A. Gödecke

Department of Cardiovascular Physiology,

Heinrich-Heine-University, Düsseldorf, Germany

M. T. Gladwin

Vascular Medicine Institute, University of Pittsburgh,

Pittsburgh, PA, USA

M. T. Gladwin

Division of Pulmonary, Allergy and Critical Care Medicine,

Department of Medicine, University of Pittsburgh School

of Medicine, Pittsburgh, PA, USA
(IS), $\mathrm{NO}_{\mathrm{x}}$ levels, $\mathrm{RBCs} \mathrm{NO}$ formation, $\mathrm{RBC}$ deformability, and vascular reactivity were assessed. At baseline, $\mathrm{BC}-$ $\mathrm{EC}+$ chimera had lower nitrite levels in blood plasma (BC-/ $\mathrm{EC}+: 2.13 \pm 0.27 \mu \mathrm{M}$ vs. $\mathrm{BC}+/ \mathrm{EC}+3.17 \pm 0.29 \mu \mathrm{M}$; $\left.{ }^{*} p<0.05\right)$, reduced DAF FM associated fluorescence within RBCs (BC-/EC+: $538.4 \pm 12.8$ mean fluorescence intensity (MFI) $\quad$ vs. $\quad \mathrm{BC}+/ \mathrm{EC}+: \quad 619.6 \pm 6.9 \quad \mathrm{MFI}$; $\left.{ }^{* * *} p<0.001\right)$ and impaired erythrocyte deformability $(\mathrm{BC}-/ \mathrm{EC}+: 0.33 \pm 0.01$ elongation index $(\mathrm{EI}) \mathrm{vs} . \mathrm{BC}+/$ $\left.\mathrm{EC}+: 0.36 \pm 0.06 \mathrm{EI} ;{ }^{*} p<0.05\right)$, while vascular reactivity remained unaffected. Area at risk did not differ, but infarct size was higher in $\mathrm{BC}-/ \mathrm{EC}+(\mathrm{BC}-/ \mathrm{EC}+: 26 \pm 3 \%$; $\mathrm{BC}+/$ $\mathrm{EC}+: 14 \pm 2 \% ; * * p<0.01)$, resulting in decreased ejection fraction $(\mathrm{BC}-/ \mathrm{EC}+46 \pm 2 \%$ vs. $\mathrm{BC}+/ \mathrm{EC}+$ : $52 \pm 2 \% ; * p<0.05)$ and increased end-systolic volume. Application of the NOS inhibitor $S$-ethylisothiourea hydrobromide was associated with larger infarct size in $\mathrm{BC}+$ / $\mathrm{EC}+$, whereas infarct size in $\mathrm{BC}-/ \mathrm{EC}+$ mice remained unaffected. Reduced infarct size, preserved cardiac function, NO levels in RBC and RBC deformability suggest a modulating role of circulating NOS3 in an acute model of myocardial I/R in chimeric mice.

Keywords Nitric oxide - Myocardial ischemia/ reperfusion $\cdot$ Circulating NOS3

\section{Introduction}

NO derived from the endothelial NO synthase (NOS3) regulates coronary blood flow, evokes positive inotropic and lusitropic effects, improves myocardial relaxation and optimizes cardiac performance [41]. NO participates in the regulation of myocardial metabolism [30]. It reduces the consumption of oxygen and the inotropic effect of 
catecholamines by muscarinic, cholinergic, and betaadrenergic receptor stimulation $[1,43]$.

During myocardial ischemia and reperfusion (I/R), NO exerts a cardioprotective role by a variety of mechanisms [15], e.g., it regulates mitochondrial respiration, thereby improving myocardial oxygenation [51]. Endogenous NO contributes to hibernation via reducing oxygen consumption and preserving calcium sensitivity and contractile function [15]. NO inactivates caspases by nitrosation and thus decreases myocyte apoptosis [15]. Whereas an increase in cardiac interstitial NO production could be observed during early I/R [29], which is in part derived from activated NOS isoforms [11], NO formation drops during ongoing $I / R$. In this acute phase, endothelium becomes dysfunctional, leukocyte adhesion increases and neutrophils migrate into the reperfused tissue. NOS3 knockout mice exhibit enlarged infarct sizes [20], while infarct size after $\mathrm{I} / \mathrm{R}$ is reduced in animals with NOS3 overexpression [17, 44], suggesting a cardioprotective role for NOS3-derived NO in the setting of I/R.

NOS3 is not only expressed in the vascular endothelium but also in blood cells including B- and T-lymphocytes [42], eosinophils [50], and in red blood cells (RBCs) [5, 24]. RBCs are the most abundant blood cell population carrying a NOS3 and represent the major storage compartment of circulating NO metabolites [7, 39]. Red cell NOS3-dependent NO production alters the functional characteristics of the erythrocyte, including erythrocyte deformability, platelet activity and vascular tone $[5,24,47]$. Thus, in addition to the vascular endothelium, the RBCs are another source of vascular NOSdependent NO production and contribute to the circulating NO pool [5, 24]. In addition, RBCs have "shuttle properties" and are able to accumulate and transport NO metabolites such as nitrite [9]. Application of RBCs with subsequent increase in NO release reduced the extent of irreversible myocardial tissue damage in isolated hearts [48].

We, therefore, hypothesized that circulating NOS3 decreases infarct size and subsequently preserves left ventricular function following myocardial $\mathrm{I} / \mathrm{R}$ injury. To selectively assess infarct size in the absence or presence of circulating NOS3, we created chimera mice lacking or carrying blood cell NOS3 by transplanting bone marrow from $\mathrm{NOS}^{-l-}$ mice or wild type (WT) into WT mice, and analyzed infarct size after 60-min closed-chest coronary occlusion followed by $24 \mathrm{~h}$ of reperfusion.

\section{Methods}

Animals

Male C57BL/6 wild-type (WT) and $\mathrm{NOS}^{-1-}$ mice (endothelial nitric oxide synthase) (C57BL/6.129/Ola-
eNOStm) [10] were kept according to federal regulations. All studies were approved by the state animal welfare commission. Mice ranged in body weight from 20 to $25 \mathrm{~g}$ and in age from 8 to 10 weeks for bone marrow transplantation.

Chimeras (irradiation and bone marrow transplantation)

To analyze the effects of the lack of NOS3 in blood cells in an acute model of myocardial I/R, we transplanted bone marrow from $\mathrm{WT}$ and $\mathrm{NOS}^{-1-}$ mice, producing chimeras which either do $(\mathrm{BC}+/ \mathrm{EC}+)$ or do not carry NOS3 in blood cells (BC-/EC+) as described previously [47] (See Online Resource 2 for detailed information).

Blood collection, RBC preparation and loading with DAF-FM

Blood was obtained from mice via heart puncture, anticoagulated with heparin and processed within $2 \mathrm{~h}$. For loading with DAF-FM diacetate, whole blood was diluted $1: 500$ to a final concentration of $\sim 1.2 \times 10^{4} \mathrm{RBC} / \mu \mathrm{l}$ in cold phosphate buffered solution (PBS) as previously described $[4,5]$. In brief, RBCs were loaded with $10 \mu \mathrm{M}$ DAF-FM diacetate for $30 \mathrm{~min}$ at room temperature in the dark, or left untreated, washed in PBS and analyzed for DAF FM-associated fluorescence in a FACS Canto II (BD Biosciences) flow cytometer. For NOS inhibition, RBC suspensions were pre-incubated for $30 \mathrm{~min}$ with $3 \mathrm{mM}$ L-NAME ( $\mathrm{L}-\mathrm{N}^{\mathrm{G}}$-nitroarginine methyl ester). The method was validated for detection of NO-related species in RBC by applying a multilevel analytical approach and separating the reaction products with RP-HPLC or LC/MS/MS, as described in [4, 5] (See Online Resource 2 for detailed information).

Measurement of nitrite/nitrate in plasma, heart tissue and aorta

Blood samples were collected by intra-cardiac puncture at baseline, after $5 \mathrm{~min}$ and $24 \mathrm{~h}$ of myocardial reperfusion. Blood and tissue samples were prepared for determination of nitrate and nitrite as previously described [12, 23, 38, 40] (See Online Resource 5 and 6 for detailed information).

Measurement of RBC deformability (ektacytometry)

Blood was drawn via heart puncture and collected in a heparinized tube for the measurement of RBC deformability. RBC deformability was measured by ektacytometry by the Laser-assisted optical rotational cell analyzer (LORCA, $\mathrm{R} \& \mathrm{R}$ Mechatronics) according to the manufacturer's instructions as previously described [16, 21]. RBC 
deformability was expressed by the elongation index (EI), which was calculated from the elliptical RBC diffraction pattern as EI $=(L-W) /(L+W)$, where $L$ and $W$ are the length and width of the diffraction pattern, respectively (See Online Resource 9 for detailed information).

\section{Langendorff setup}

For isolated heart measurements, murine hearts were explanted at baseline (6 weeks after bone marrow transplantation), and mounted with retrograde perfusion at $100 \mathrm{mmHg}$ constant pressure with modified KrebsHenseleit buffer in an isolated heart apparatus (Hugo Sachs Elektronik), as previously described [31-33, 46] (See Online Resource 2 for detailed information).

Gel electrophoresis and western blot analysis

Mouse heart, mouse aorta and human endothelial cells were lysed with RIPA lysis buffer containing protease inhibitor cocktail (Roche Applied Science), as previously described [5, 47]. Total protein concentration was determined by the Lowry assay (DC Protein Assay, Bio-Rad). For gel electrophoresis, $80 \mu \mathrm{g}$ heart lysates, $20 \mu \mathrm{g}$ aortic lysates, or human umbilical endothelial cell lysate were loaded in 4-12\% Bis-Tris gel. For western blot analysis, proteins were transferred onto polyvinylidene fluoride membrane Hybond P (Amersham Biosciences, Munich, Germany). A pre-stained protein ladder (PageRuler Plus, Fermentas Life Science) was loaded into the gel to control for transfer efficiency. The membrane was blocked with $5 \%$ nonfat dry milk (Bio-Rad) in TBS $(10 \mathrm{mM}$ Tris, $100 \mathrm{mM} \mathrm{NaCl}$ ), incubated with a mouse anti-human antieNOS antiserum (overnight $4{ }^{\circ} \mathrm{C}$ 1:500) (BD Bioscience) diluted (1 h RT 1:1,000) in T-TBS (0.1\% Tween in TBS), washed for $30 \mathrm{~min}$ in T-TBS, and then incubated with HRP-conjugated goat anti-mouse antibody $(1: 5,000)$ from (BD Bio science).

Isometric force measurements in aortic rings

Thoracic aorta was removed as previously described at baseline (6 weeks after bone marrow transplantation) [45, 46]. Aortic rings were placed in an organ bath (Model Graz, Type 846, Hugo Sachs), under $1 \mathrm{~g}$ of tension, and bathed in $2 \mathrm{~mL}$ of Krebs buffer constantly gassed with $95 \% \mathrm{O}_{2} / 5 \% \mathrm{CO}_{2}$ at $37{ }^{\circ} \mathrm{C}$. After equilibration phase (90 $\mathrm{min}$ ), tissues were exposed to potassium chloride $(80 \mathrm{nM})$ and subsequently phenylephrine $(1 \mu \mathrm{M})$ to achieve maximal contraction. Afterwards relaxation response curves to increasing concentrations of acetylcholine $(1 \mathrm{nM}-10 \mu \mathrm{M})$ or to increasing concentrations of the NO donor sodium nitroprusside (SNP) $(0.001-10 \mu \mathrm{M})$ were constructed. Contractility response to increasing concentrations of phenylephrine $(1 \mathrm{nM}-10 \mu \mathrm{M})$ was measured.

Myocardial ischemia and reperfusion protocol

A closed-chest model of myocardial $\mathrm{I} / \mathrm{R}$ was utilized 6 week after bone marrow transplantation to reduce surgical trauma and consequent inflammatory reaction following I/R as compared to open-chest model [36]. At 3-day post-instrumentation myocardial ischemia was induced for $60 \mathrm{~min}$ of ischemia followed by $24 \mathrm{~h}$ of reperfusion (See Online Resource 2 for detailed information).

Assessment of infarct size (IS)

After $24 \mathrm{~h}$ of reperfusion, the animals were killed and heart was excised, rinsed in $0.9 \%$ normal saline, left anterior descending artery (LAD) was re-occluded in the same location and $1 \%$ Evans Blue dye was injected into the aortic root to delineate the area at risk (AAR) from not-atrisk myocardium, as published recently [14] (See Online Resource 2 for detailed information).

\section{Echocardiography}

Cardiac images were acquired using a Vevo 2100 highresolution ultrasound scanner with $18-38 \mathrm{MHz}$ linear transducer (VisualSonics Inc.). Echocardiography was performed as previously described [26]. Left ventricular (LV) end-systolic (ESV), end-diastolic volumes (EDV), LV ejection fraction (EF), cardiac output (CO) and stroke volume (SV) were calculated (See Online Resource 8 for detailed information).

\section{ETU treatment}

A subgroup of animals received $S$-ethylisothiourea hydrobromide (ETU) to achieve systemic NOS inhibition during ischemia and the first $5 \mathrm{~min}$ of reperfusion. During whole ischemia $(60 \mathrm{~min})$ and the first $5 \mathrm{~min}$ of reperfusion, ETU was administered at $(0.245 \mu \mathrm{g} / \mu \mathrm{l} / \mathrm{min}$; i.p.) [46]. After $24 \mathrm{~h}$ of reperfusion, LV function was measured via echocardiography and infarct size was measured via triphenyltetrazoliumchlorid (TTC) staining in this subgroup.

Statistical analysis

The results are given as mean \pm standard error of the mean (SEM). For repeated measurements, data were analyzed by two-way ANOVA followed by Bonferroni's post hoc test. Where indicated, an unpaired Student's $t$ test was applied. $p=0.05$ was set as the threshold of significance. 


\section{Results}

Baseline characterization of chimeras after bone marrow transplantation

\section{Inflammation}

6 weeks after bone marrow transplantation, blood counts of both groups did not differ except for mean platelet volume $\left(\mathrm{BC}+/ \mathrm{EC}+: \quad 5.75 \pm 0.33 \mu \mathrm{m}^{3} ; n=21\right.$ vs. $\mathrm{BC}-/ \mathrm{EC}+$ : $\left.5.07 \pm 0.18 \mu \mathrm{m}^{3} ; n=16 * * * p<0.001\right)$ and lymphocytes $\left(\mathrm{BC}+/ \mathrm{EC}+: 0.93 \pm 0.2310^{3} / \mathrm{mm}^{3} ; n=21 \mathrm{vs} . \mathrm{BC}-/ \mathrm{EC}+\right.$ : $1.69 \pm 1.1810^{3} / \mathrm{mm}^{3} ; n=16 ; * p<0.05$ ) (See Online Resource 3 for detailed information). To analyze for chronic persisting inflammation as a result of the transplantation, serum amyloid $\mathrm{P}$ (SAP) levels were determined in plasma via ELISA. No differences were seen between the groups $(\mathrm{BC}+/$ $\mathrm{EC}+: \quad 68.1 \pm 6.2 \mu \mathrm{g} / \mathrm{ml} ; \quad n=23 \quad$ and $\quad \mathrm{BC}-/ \mathrm{EC}+$ $64.7 \pm 9.7 \mu \mathrm{g} / \mathrm{ml}, n=19$; n.s.) in blood plasma 6 weeks after bone marrow transplantation (See Online Resource 4).

$N O_{x}$ levels

$\mathrm{BC}-/ \mathrm{EC}+$ chimera showed a decreased DAF-FM associated fluorescence within RBCs (BC-/EC+: $538.4 \pm 12.8$
MFI) as compared to $\mathrm{BC}+/ \mathrm{EC}+$ mice $(619.6 \pm 6.9 \mathrm{MFI}$, $* * * p<0.001, n=5$ per group) 6 weeks after bone marrow transplantation (See Fig. 1a). The background signal observed in $\mathrm{RBC}$ from $\mathrm{BC}-/ \mathrm{EC}+$ mice is not different from that obtained by loading human $\mathrm{RBC}$ treated with L-NAME (observed before [5]), and is due to the formation of fluorescent adducts of DAF-FM with molecules such as ascorbate, particularly abundant in $\mathrm{RBC}$, and to the presence of fluorescent impurities in the stock solutions of DAF-FM DA, which are detectable only by analytical separative techniques as described previously [4]. Results provided evidence for a diminished NO formation in $\mathrm{RBC}$ under normoxic conditions in $\mathrm{BC}-/ \mathrm{EC}+$.

Nitrite levels in $\mathrm{BC}-/ \mathrm{EC}+$ chimera $(2.13 \pm 0.27 \mu \mathrm{M}$; $n=11$ ) were lower in plasma compared to $\mathrm{BC}+/ \mathrm{EC}+$ mice $(3.17 \pm 0.29 \mu \mathrm{M} ; n=10 ; * p<0.05)$ at baseline (See Fig. 1c). Nitrate levels were slightly but not significantly reduced in $\mathrm{BC}-/ \mathrm{EC}+(121.60 \pm 16.37 \mu \mathrm{M}$; $n=11) \quad$ compared to $\mathrm{BC}+/ \mathrm{EC}+$ mice $(189.09 \pm$ $22.77 \mu \mathrm{M} ; n=10$; n.s.) at baseline (See Fig. 1d). Nitrite $(\mathrm{BC}+/ \mathrm{EC}+: 1.36 \pm 0.15 \mu \mathrm{M}, \quad n=4$ vs. $\mathrm{BC}-/ \mathrm{EC}+$ : $1.53 \pm 0.22 \mu \mathrm{M}, \quad n=3 ; \quad$ n.s. $)$ and nitrate $(\mathrm{BC}+/$ $\mathrm{EC}+: 18.31 \pm 4.10 \mu \mathrm{M}, \quad n=4 \quad$ vs. $\quad \mathrm{BC}-/ \mathrm{EC}+$ : $27.07 \pm 7.14 \mu \mathrm{M}, n=3$; n.s.) levels in heart tissue did not differ between both groups at baseline (i.e., 6-week post-

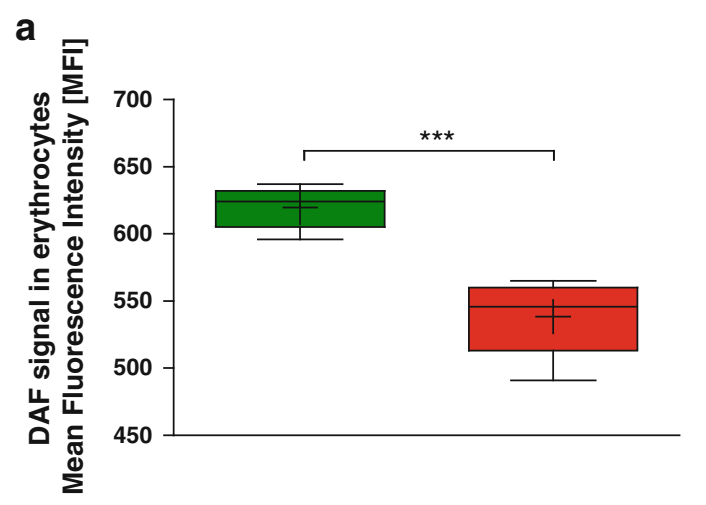

C

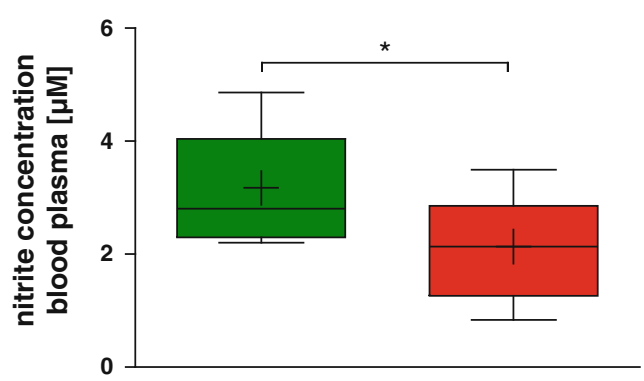

Fig. 1 Depletion of circulating NOS3 reduces NO bioavailability, RBC deformability, and plasma levels of nitrite and nitrate. Decreased DAF signal within erythrocytes (a, $n=5$ per group, *** $p<0.001$, unpaired Student's $t$ test), reduced erythrocyte deformability $(\mathbf{b}, \mathrm{BC}+/ \mathrm{EC}+n=15, \mathrm{BC}-/ \mathrm{EC}+n=16$, * $p<0.05$, two-
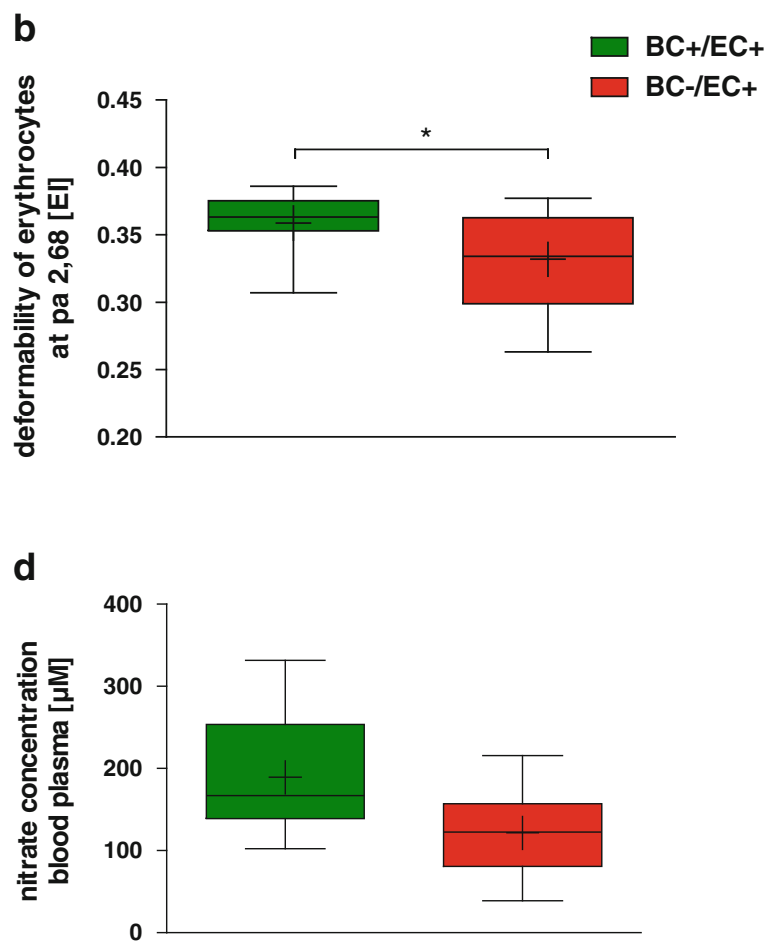

way ANOVA followed by Bonferroni's post hoc test) and diminished nitrite $\left(\mathbf{c} ; \mathrm{BC}+/ \mathrm{EC}+n=10, \mathrm{BC}-/ \mathrm{EC}+n=11,{ }^{*} p<0.05\right.$, twoway ANOVA followed by Bonferroni's post hoc test) and nitrate plasma levels $(\mathbf{d} ; \mathrm{BC}+/ \mathrm{EC}+n=10, \mathrm{BC}-/ \mathrm{EC}+n=11$; n.s. $)$ were measured in $\mathrm{BC}-/ \mathrm{EC}+$ compared to $\mathrm{BC}+/ \mathrm{EC}+$ at baseline 
bone marrow transplantation) (See Online Resource 5). Likewise, nitrite $(\mathrm{BC}+/ \mathrm{EC}+: 1.07 \pm 0.10 \mu \mathrm{M}, n=3$ vs. $\mathrm{BC}-/ \mathrm{EC}+: \quad 1.01 \pm 0.07 \mu \mathrm{M}, \quad n=3$; n.s.) and nitrate $(\mathrm{BC}+/ \mathrm{EC}+: \quad 41.61 \pm 12.56 \mu \mathrm{M}, n=3$ vs. $\mathrm{BC}-/ \mathrm{EC}+$ : $31.51 \pm 6.81 \mu \mathrm{M}, n=3$; n.s.) levels in aorta did not differ between both groups at baseline (i.e., 6-week post-bone marrow transplantation) (See Online Resource 6).

\section{RBC deformability}

6 weeks after bone marrow transplantation, $\mathrm{BC}-/ \mathrm{EC}+$ $(0.33 \pm 0.01 \mathrm{EI} ; n=16$ per group) exhibited decreased $\mathrm{RBC}$ deformability compared to $\mathrm{BC}+\mathrm{EC}+(0.36 \pm 0.01$ EI; $n=15$; $* p<0.05$ ) (See Fig. 1b). Both groups demonstrated diminished RBC deformability compared to nonirradiated wild type 6 weeks after transplantation $(0.39 \pm 0.01 \mathrm{EI} ; n=15 ; * * * p<0.001)$.

\section{Vascular reactivity}

The effects of the transplantation procedure on vascular reactivity were assessed with three independent approaches. Ex vivo measurements of coronary flow (isolated hearts, Langendorff setup) of $\mathrm{BC}+/ \mathrm{EC}+$ and $\mathrm{BC}-/ \mathrm{EC}+$ revealed no differences in basal coronary flow $(\mathrm{BC}+/ \mathrm{EC}+$ : basal: $\quad 18.84 \pm 1.91 \mathrm{ml} / \mathrm{min} / \mathrm{g}$ vs. $\mathrm{BC}-/ \mathrm{EC}+$ : basal: $15.07 \pm 1.08 \mathrm{ml} / \mathrm{min} / \mathrm{g}$, n.s.). After global brief ischemia, both groups responded with a uniform increase in coronary flow (BC+/EC+: basal: $18.84 \pm 1.91 \mathrm{ml} / \mathrm{min} / \mathrm{g}$ vs. reperfusion: $\quad 47.11 \pm 1.67 \mathrm{ml} / \mathrm{min} / \mathrm{g}, \quad * * * p<0.001, \quad n=7$; $\mathrm{BC}-/ \mathrm{EC}+$ : basal: $15.07 \pm 1.08 \mathrm{ml} / \mathrm{min} / \mathrm{g}$ vs. reperfusion: $41.90 \pm 2.94 \mathrm{ml} / \mathrm{min} / \mathrm{g}, \quad * * * p<0.001, \quad n=8) \quad$ (See Fig. 2a).

In vivo measurement of vascular reactivity was assessed by laser Doppler perfusion imaging, as changes in reactive

\section{Coronary resistance vessels}
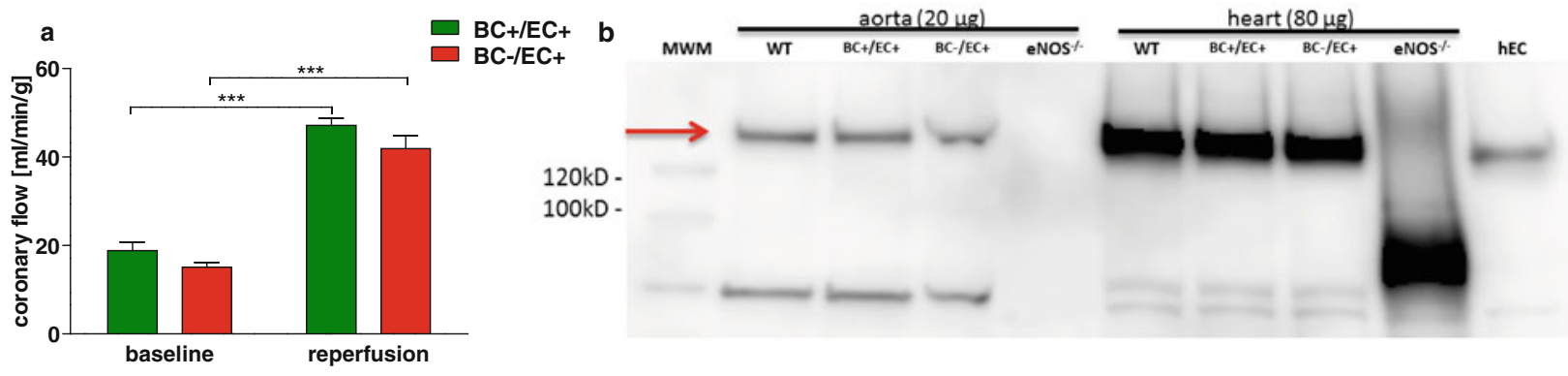

\section{conductance vessels - aorta}
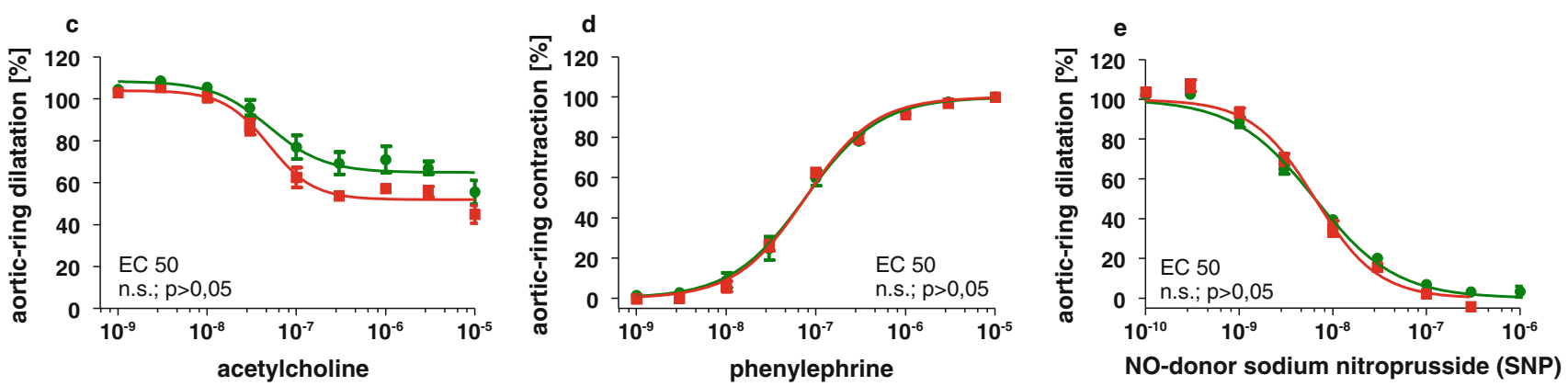

Fig. 2 Comparison of NOS3 expression and endothelial function in chimeric and WT mice. Ex vivo measurements of coronary flow from isolated hearts in Langendorff setup (a) of $\mathrm{BC}+/ \mathrm{EC}+$ and $\mathrm{BC}-/ \mathrm{EC}+$ revealed no significant differences at baseline and after global ischemia (flow corrected for heart weight; $\mathrm{BC}+/ \mathrm{EC}+n=7, \mathrm{BC}-/$ $\mathrm{EC}+n=8$, n.s.). NOS3 expression in hearts from $\mathrm{BC}+/ \mathrm{EC}+, \mathrm{BC}-1$ $\mathrm{EC}+$ and WT mice was assessed by Western blot analysis and compared with NOS3 expression in aortic tissue. No differences were detected between the displayed groups, while heart tissue exhibited overall higher NOS3 level than aortic tissue (b). Isometric force measurements in aortic rings $(\mathbf{c}-\mathbf{e}) . \mathrm{BC}+/ \mathrm{EC}+$ and $\mathrm{BC}-/ \mathrm{EC}+$ revealed no significant difference in the mean effective concentration (EC 50) and, therefore, no different vessel characteristics at baseline ( $n=5$ per group, n.s., EC50 tested with unpaired Student's $t$ test) 
hyperemic response following short-term vascular occlusion in the hind limb of $\mathrm{BC}+/ \mathrm{EC}+$ and $\mathrm{BC}-/ \mathrm{EC}+$ mice. The measurements revealed no differences in all parameters investigated (See Online Resource 7). Basal mean perfusion before induction of hind limb ischemia $(\mathrm{BC}+/$ $\mathrm{EC}+: \quad 99 \pm 5 \% ; \quad n=14 ; \quad \mathrm{BC}-/ \mathrm{EC}+: \quad 106 \pm 6 \%$; $n=12$; n.s.), the time till reperfusion peak (maximum mean perfusion) (BC+/EC+: $42 \pm 3 \mathrm{~s} ; n=14$; $\mathrm{BC}-/$ $\mathrm{EC}+: 43 \pm 3 \mathrm{~s} ; n=12$; n.s.) and the area under the curve of the reperfusion signal $(\mathrm{BC}+/ \mathrm{EC}+: 1.106 \pm 56 ; n=14$ $\mathrm{BC}-/ \mathrm{EC}+: \quad 1.186 \pm 91 ; n=12 ;$ n.s.) did not differ between both groups.

Vascular reactivity of aortic rings from $\mathrm{BC}+/ \mathrm{EC}+$ and $\mathrm{BC}-/ \mathrm{EC}+$ mice was compared by wire myography. After pre-contraction with $\mathrm{KCl}$ response curves to acetylcholine, phenylephrine and SNP were determined as the response of EC50 to the applied substances. For all three conditions, no difference in the mean effective concentration (EC 50) and, therefore, no differences in endothelium-dependent and endothelium-independent vascular function were observed (See Fig. 2c-e).

\section{NOS3 levels in heart and aorta}

NOS3 expression in the heart and aorta from $\mathrm{BC}+/ \mathrm{EC}+$, $\mathrm{BC}-/ \mathrm{EC}+$ and WT mice was assessed by Western blot analysis. No differences were detected between the analyzed groups (See Fig. 2b).

\section{Left ventricular function}

Depletion of blood cell NOS3 did not modify left ventricular function at baseline (6 weeks after bone marrow transplantation) as determined by M-mode and B-mode measurements, indicating equal left ventricular function in $\mathrm{BC}-/ \mathrm{EC}+$ compared to $\mathrm{BC}+/ \mathrm{EC}+$.

Left ventricular ejection fraction $(\mathrm{BC}+/ \mathrm{EC}+$ : $61 \pm 1 \%$; BC-/EC+: $62 \pm 1 \%$; n.s), end-systolic volume (BC+/EC+: $25 \pm 1 \mu \mathrm{l}$; $\mathrm{BC}-/ \mathrm{EC}+: 25 \pm 1 \mu \mathrm{l}$; n.s $)$ and end-diastolic volume (BC+/EC+: $66 \pm 2 \mu \mathrm{l}, n=22$; $\mathrm{BC}-/ \mathrm{EC}+: \mathrm{6} \pm 2 \mu \mathrm{l}, n=25$; n.s.) did not differ between both groups (See Fig. 4 and Online Resource 8).

Response of chimeras to myocardial ischemia/ reperfusion

Blood cell NOS3 reduces infarct size following myocardial ischemia/reperfusion

Infarct size was increased in $\mathrm{BC}-/ \mathrm{EC}+$ compared to $\mathrm{BC}+/$ $\mathrm{EC}+\quad(\mathrm{BC}-/ \mathrm{EC}+: \quad 26 \pm 3 \% ; \quad n=6 ; \quad \mathrm{BC}+/ \mathrm{EC}+$ : $14 \pm 2 \% ; n=9$ per group; $* * p<0.01)$, while AAR per $\mathrm{LV}$ did not differ between both groups (BC-/EC+:
$50 \pm 1 \% ; n=6 \mathrm{BC}+/ \mathrm{EC}+: 51 \pm 2 \% ; n=9$ per group; n.s.) (See Fig. 3).

\section{Left ventricular function after 24 h of reperfusion}

After $24 \mathrm{~h}$ of reperfusion, systolic left ventricular function was impaired with reduced ejection fraction $(\mathrm{BC}-/ \mathrm{EC}+$ $46 \pm 2 \% ; n=19$ vs. $\mathrm{BC}+/ \mathrm{EC}+: 52 \pm 2 \% ; n=21$; $* p<0.05$ ) (See Fig. 4 and Online Resource 8) and increased end-systolic volume (BC-/EC+: $41 \pm 2 \mu \mathrm{l} ; n=19$ vs. $\mathrm{BC}+/ \mathrm{EC}+: 34 \pm 3 \mu \mathrm{l} ; n=21 ; * p<0.05)$ in $\mathrm{BC}-/ \mathrm{EC}+$ compared to $\mathrm{BC}+/ \mathrm{EC}+($ See Online Resource 8$)$.

\section{ETU treatment}

Application of the global NOS inhibitor ETU was associated with increased infarct size (ETU: $36 \pm 3 \% ; n=6$ vs. without ETU: $14 \pm 2 \% ; n=9 ; * p<0.05)$ in $\mathrm{BC}+/ \mathrm{EC}+$, whereas $\mathrm{BC}-/ \mathrm{EC}+$ demonstrated no differences after
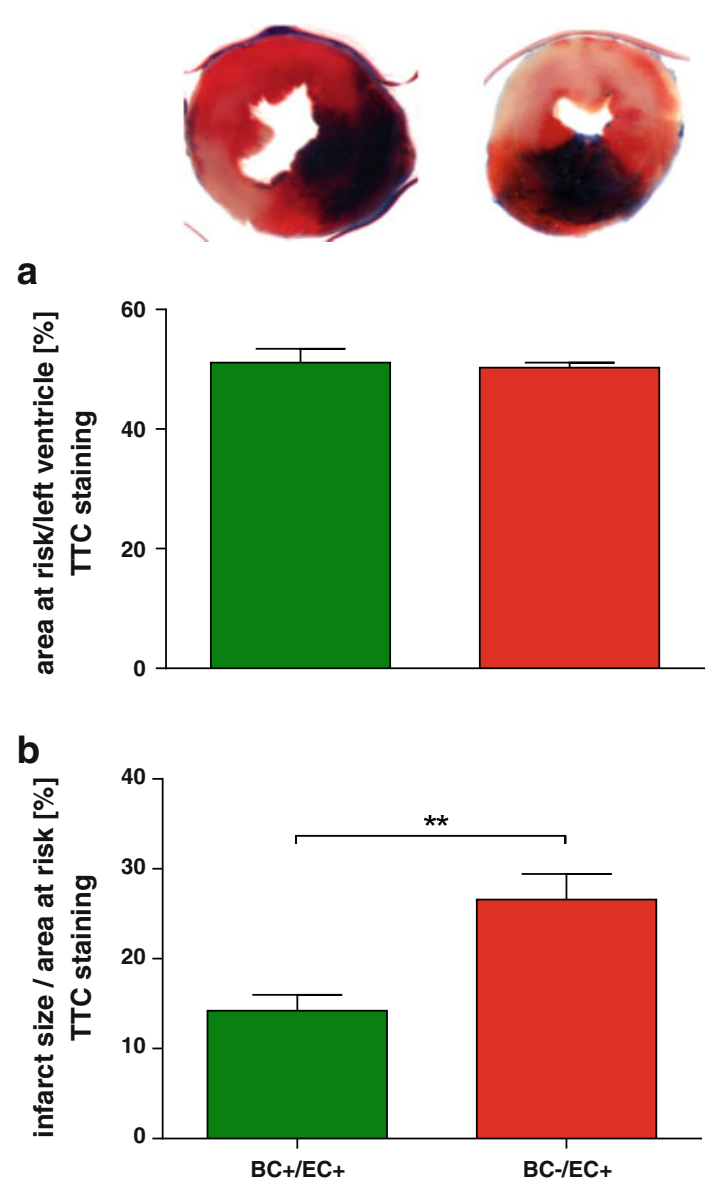

Fig. 3 Depletion of circulating NOS3 increases infarct size following acute myocardial ischemia/reperfusion. While AAR per LV did not differ between both groups, infarct sizes were significantly increased in $\mathrm{BC}-/ \mathrm{EC}+(n=6)$ compared to $\mathrm{BC}+/ \mathrm{EC}+(n=9$, $* * p<0.01$, unpaired Student's $t$ test) 


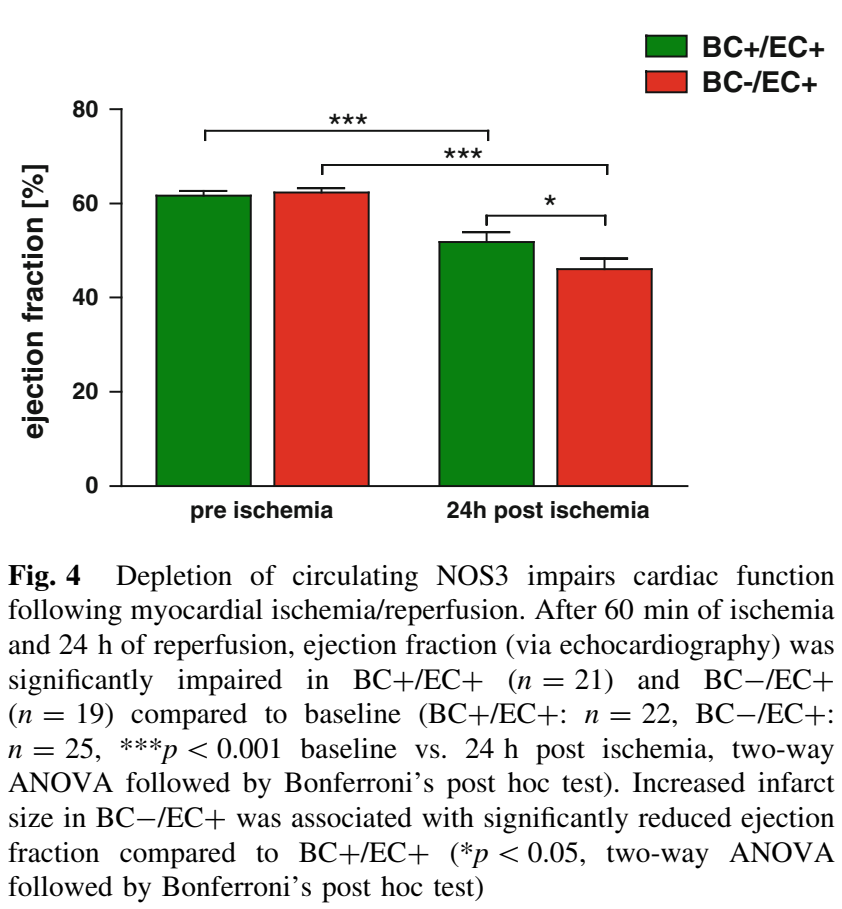

followed by Bonferroni's post hoc test)

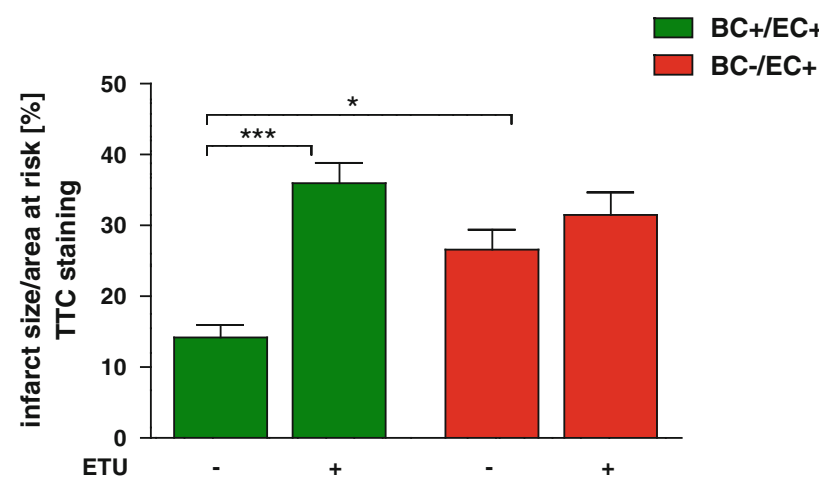

Fig. 5 Circulating NOS3 contributes to reduced infarct size. Application of the global NOS inhibitor S-ethylisothiourea hydrobromide (ETU) was associated with a further increase in infarct size in $\mathrm{BC}+/ \mathrm{EC}+$ (without ETU $n=9$; with ETU $n=6$; *** $p<0.001$; one-way ANOVA followed by Bonferroni's post hoc test), whereas $\mathrm{BC}-/ \mathrm{EC}+$ (without and with ETU $n=6$ ) demonstrated no significant differences after global NOS inhibition

global NOS inhibition (ETU: $32 \pm 3 \% ; n=6$ without ETU: $27 \pm 3 \% ; n=6$; n.s.) (See Fig. 5).

\section{Nitrite in early and late reperfusion: blood cell NOS3 contributes to endogenous $N O$ pool and improves $N O$ bioavailability in the early reperfusion phase}

Blood plasma nitrite levels were slightly reduced in $\mathrm{BC}-1$ $\mathrm{EC}+$ plasma at $5 \mathrm{~min}(\mathrm{BC}-/ \mathrm{EC}+: 0.90 \pm 0.18 \mu \mathrm{M}$ vs. $\mathrm{BC}+/ \mathrm{EC}+: 1.95 \pm 0.41 \mu \mathrm{M} ; n=4$ per group; n.s.) and $24 \mathrm{~h}$ of reperfusion $(\mathrm{BC}-/ \mathrm{EC}+: 1.21 \pm 0.18 \mu \mathrm{M} ; n=7$ vs. $\mathrm{BC}+/ \mathrm{EC}+: 1.56 \pm 0.26 \mu \mathrm{M} ; n=6$; n.s.) compared to
$\mathrm{BC}+/ \mathrm{EC}+($ See Online Resource 9a). Nitrate concentration in plasma was significantly reduced in $\mathrm{BC}-/ \mathrm{EC}+$ (5 min: $\quad 95.45 \pm 21.40 \mu \mathrm{M} ; \quad n=4 \quad$ and $\quad 24 \mathrm{~h}$ : $74.38 \pm 7.42 \mu \mathrm{M} ; n=5)$ compared to $\mathrm{BC}+/ \mathrm{EC}+(5 \mathrm{~min}:$ $224.12 \pm 57.12 \mu \mathrm{M} ; \quad n=4 ; \quad * p<0.05$ and $24 \mathrm{~h}$ : $178.84 \pm 16.37 \mu \mathrm{M} ; n=6 ; * p<0.05)$ at $5 \mathrm{~min}$ and $24 \mathrm{~h}$ of reperfusion (See Online Resource 9b). Nitrite and nitrate concentration in heart tissue did not differ between both groups at $5 \mathrm{~min}$ (nitrite: $\mathrm{BC}+/ \mathrm{EC}+$ : $1.42 \pm 0.24 \mu \mathrm{M}$; $\mathrm{BC}-/ \mathrm{EC}+: \quad 1.36 \pm 0.23 \mu \mathrm{M}, \quad n=4$ per group, n.s.; nitrate: $\mathrm{BC}+/ \mathrm{EC}+: 21.92 \pm 1.74 \mu \mathrm{M}, n=3$ vs. $\mathrm{BC}-/$ $\mathrm{EC}+: 12.32 \pm 2.17 \mu \mathrm{M}, n=4$, n.s) and $24 \mathrm{~h}$ of reperfusion (nitrite: $\mathrm{BC}+/ \mathrm{EC}+$ : $0.41 \pm 0.06 \mu \mathrm{M}$ vs. $\mathrm{BC}-/ \mathrm{EC}+$ : $0.31 \pm 0.12 \mu \mathrm{M}, n=3$ per group, n.s.; nitrate: $\mathrm{BC}+/$ $\mathrm{EC}+: 12.78 \pm 0.48 \mu \mathrm{M}$ vs. $\mathrm{BC}-/ \mathrm{EC}+: 13.67 \pm 4.09 \mu \mathrm{M}$, $n=3$ per group; n.s.).

\section{Blood cell NOS3 preserved erythrocyte deformability 24-h post-ischemia}

RBC deformability was diminished in $\mathrm{BC}-/ \mathrm{EC}+$ $(0.27 \pm 0.01 \quad \mathrm{EI} ; \quad n=16)$ compared to $\mathrm{BC}+/ \mathrm{EC}+$ $(0.35 \pm 0.01 \mathrm{EI} ; n=15 ; * * *<0.001) 24 \mathrm{~h}$ after reperfusion. Furthermore, $\mathrm{BC}-/ \mathrm{EC}+$ showed a decrease in RBC deformability after $24 \mathrm{~h}$ of reperfusion compared to baseline $(0.33 \pm 0.01 \mathrm{EI} ; n=16 ; * * p<0.05)$. In contrast, RBC deformability was not affected by I/R in BC+/EC+ chimeras $(0.36 \pm 0.06 \mathrm{EI} ; n=15 ;$ n.s.) (See Online Resource 9c).

\section{Discussion}

The main findings of the present study are: (1) circulating NOS3 reduces infarct size in a myocardial ischemia/ reperfusion model of chimeric mice; (2) this translates into a sustained reduction of LV function; (3) depletion of circulating NOS3 reduces circulating NO pool by $1 / 3$, as evidenced by reduced plasma levels of nitrite; (4) circulating NOS3 limits RBC deformability.

In the present study, depletion of circulating NOS3 is associated with increased infarct size and impaired left ventricular function. In accordance with these findings, global depletion of $\mathrm{NOS}^{-1-}$ increased infarct size and impaired LV function after I/R [20], and conventional wisdom holds that these effects are primarily determined by the lack of NOS3 in the vessel endothelium. Our data suggest that endothelial NOS3 is unable to compensate for the depletion of circulating NOS3 alone in terms of reduction of tissue damage and preservation of left ventricular function as a result of myocardial $\mathrm{I} / \mathrm{R}$ in the current chimeric model. It is conceivable that endothelial dysfunction, which occurs during $\mathrm{I} / \mathrm{R}$ and is associated with 
endothelial NOS3 uncoupling, limits the functional capacity of endothelial NOS3 [8]. We did not find any differences in vascular function in the two mice groups, as assessed in both conductance and resistance vessels. Thus, we exclude that differences in endothelial functionality between groups might have caused differences in infarct size. In the context of myocardial ischemia, NOS inhibition exacerbates myocardial I/R injury [25]. In our study, application of the global NOS inhibitor ETU was associated with increased infarct size in $\mathrm{BC}+/ \mathrm{EC}+$, whereas $\mathrm{BC}-/ \mathrm{EC}+$ demonstrated no differences after global NOS inhibition. Therefore, circulating NOS3 limits infarct size and this translates into preserved LV function in a myocardial I/R model.

We examined nitrite and nitrate levels in plasma and heart tissue as a marker of systemic NO bioavailability at baseline, $5 \mathrm{~min}$ and $24 \mathrm{~h}$ after ischemia. Both groups showed a significant decrease in nitrite plasma levels 5 min after ischemia compared to baseline. Whereas mice with depleted circulating NOS3 show more reduced plasma nitrite levels compared to animals carrying circulating NOS at baseline and $5 \mathrm{~min}$ after ischemia. However, nitrite heart tissue levels remain stable and show no difference between both groups at all examined time points. Both groups are obviously able to maintain their nitrite/nitrate concentration to a certain degree in the analyzed tissues (heart and aorta) at baseline and at least in the first 5 min of reperfusion independently of surrounding plasma levels. Therefore, depletion of circulating NOS3 was associated with nitrite levels reduced by $1 / 3$ at baseline compared to animals carrying circulating NOS3 only in plasma but not in heart tissue. These data confirm and expand recent findings in chimera obtained from the two further existing $\mathrm{NOS}^{-1-}$ strains [47] other than the one used in this study, and demonstrate that circulating NOS3 plays a central role in determining the circulating NO pool. These reduced levels of circulating nitrite likely contribute to the greater tissue damage in $\mathrm{BC}-/ \mathrm{EC}+$ chimeras, as previously shown in WT mice $[13,14]$. Nevertheless, the exact quantitative contribution of circulating NOS3 to the circulating nitric oxide metabolite $\left(\mathrm{NO}_{\mathrm{x}}\right)$ pool cannot be assessed accurately without analyzing nitrite/nitrate content in whole blood and the differentially in the individual blood cell types as well as plasma. While this was not primarily the aim of the present study, it certainly represents a limitation and should be addressed in further studies.

The organism is able to reduce nitrite to NO, thus potentially compensating for an impaired NOS activity/NO bioavailability, [6]. Nitrite is, therefore, considered as an "ischemic NO buffer" [14]. Various nitrite reductases exist, which are effective at different oxygen partial pressures along the vascular tree: (1) hemoglobin, which reduces nitrite at $20-60 \mathrm{mmHg}$ oxygen, (2) myoglobin, which is active below $4 \mathrm{mmHg}$ oxygen, and (3) xanthine oxidase and the acidic reduction which reduce nitrite at $0 \mathrm{mmHg}$ oxygen and low $\mathrm{pH}$ [28]. In mice feed with a controlled nitrite/nitrate low diet, both the circulating and the endothelial NOS3 contribute to 70-90\% of the total plasma nitrite levels [22, 24]. Chimeras exhibit elevated plasma nitrite levels compared to non-transplanted wild types. This might be related to a chronic inflammation within the bone marrow due to a subclinical rejection [27]. A strong persisting systemic inflammation was excluded in the chimeras of the present study by determining the concentration of SAP in the blood plasma, a well-established murine marker of inflammation [37], and by serial assessment of white blood cells counts. As discussed above, the lower nitrite levels in $\mathrm{BC}-/ \mathrm{EC}+$ chimera indicate the contribution of circulating NOS3 to nitrite bioavailability. NO itself and nitrite, both emerging from constitutive endothelial and blood born NOS3 activity, may contribute to the cardioprotective effect in the reperfused myocardium.

During circulation, RBCs constantly change their shape as they are exposed to a range of dynamic shear stresses, and are able to respond to these forces by changing their shape [3]. This property of RBCs is defined as deformability and contributes to blood fluidity, blood flow and the passage of RBCs through capillaries with diameters smaller than their resting diameter $[35,49]$. In the present study, we found that depletion of circulating NOS3 was associated with reduced RBC deformability, as previously shown in human RBC treated with NOS inhibitors [2] and a further reduction of $\mathrm{RBC}$ deformability was measured in $\mathrm{BC}-/ \mathrm{EC}+$ mice following myocardial I/R and may contribute to myocardial damage. In fact, in patients with coronary artery disease (CAD) and diabetes mellitus, pathological alterations of hemostatic and hemorheological properties have been found to be associated with an increased incidence of coronary events [18, 19] and contribute to increased morbidity of these patients due to disturbances in blood flow [21]. Furthermore, it is known that oxidative stress and impaired NO bioavailability are able to reduce the deformability of RBCs [34]. A more extensive reduction of NO bioavailability and increase of ROS concentration within RBCs are probable reasons for the further decrease in deformability of RBCs in the $\mathrm{BC}-/$ $\mathrm{EC}+$ group compared to group $\mathrm{BC}+/ \mathrm{EC}+$ after myocardial I/R. The preserved deformability of RBCs as observed in $\mathrm{BC}+/ \mathrm{EC}+$ mice might positively impact coronary blood flow particularly in the border zone of an ischemic area and thus might also contribute to reduce infarct size and limited left ventricular function in our model of myocardial I/R.

In conclusion, we here present evidence that circulating NOS3 reduced infarct size leading to sustained left ventricular dysfunction in an acute model of myocardial I/R in 
chimeric mice. Depletion of circulating NOS3 reduces NO bioavailability and limits RBC deformability in this model. For future analyses of mechanisms underlying the protective effects of circulating NOS3 in I/R injury, it would certainly be beneficial to use a conditional erythrocytespecific knockout model to exclude any confounding factors due to irradiation/bone marrow transplantation and to identify the specific role of blood cell subpopulations in these effects.

Acknowledgments This work was supported in part by ME1821/23 to MWM and ME1821/3-1 [FOR809] to MWM and MK, RA969/42 and RA969/7-1 to TR and KE405/5-1 to MK and the SusanneBunnenberg-Stiftung at Düsseldorf Heart Center. We thank S. Becher, R. Taskesen for excellent technical assistance and Sivatharsini Thasian-Sivarajah for performing the western blot analysis.

Conflict of interest On behalf of all authors, the corresponding author states that there is no conflict of interest.

Open Access This article is distributed under the terms of the Creative Commons Attribution License which permits any use, distribution, and reproduction in any medium, provided the original author(s) and the source are credited.

\section{References}

1. Balligand JL, Feron O, Dessy C (2009) eNOS activation by physical forces: from short-term regulation of contraction to chronic remodeling of cardiovascular tissues. Physiol Rev 89:481-534. doi:10.1152/physrev.00042.2007

2. Bor-Kucukatay M, Wenby RB, Meiselman HJ, Baskurt OK (2003) Effects of nitric oxide on red blood cell deformability. Am J Physiol Heart Circ Physiol 284:H1577-H1584. doi:10.1152/ ajpheart.00665.2002

3. Chien S (1987) Red cell deformability and its relevance to blood flow. Annu Rev Physiol 49:177-192. doi:10.1146/annurev.ph.49. 030187.001141

4. Cortese-Krott MM, Rodriguez-Mateos A, Kuhnle GG, Brown G, Feelisch M, Kelm M (2012) A multilevel analytical approach for detection and visualization of intracellular NO production and nitrosation events using diaminofluoresceins. Free Radic Biol Med 53:2146-2158. doi:10.1016/j.freeradbiomed.2012.09.008

5. Cortese-Krott MM, Rodriguez-Mateos A, Sansone R, Kuhnle GG, Thasian-Sivarajah S, Krenz T, Horn P, Krisp C, Wolters D, Heiss C, Kroncke KD, Hogg N, Feelisch M, Kelm M (2012) Human red blood cells at work: identification and visualization of erythrocytic eNOS activity in health and disease. Blood 120:4229-4237. doi:10.1182/blood-2012-07-442277

6. Cosby K, Partovi KS, Crawford JH, Patel RP, Reiter CD, Martyr S, Yang BK, Waclawiw MA, Zalos G, Xu X, Huang KT, Shields H, Kim-Shapiro DB, Schechter AN, Cannon RO 3rd, Gladwin MT (2003) Nitrite reduction to nitric oxide by deoxyhemoglobin vasodilates the human circulation. Nat Med 9:1498-1505. doi:10. 1038/nm954

7. Dejam A, Hunter CJ, Pelletier MM, Hsu LL, Machado RF, Shiva S, Power GG, Kelm M, Gladwin MT, Schechter AN (2005) Erythrocytes are the major intravascular storage sites of nitrite in human blood. Blood 106:734-739. doi:10.1182/blood-2005-020567
8. Dumitrescu C, Biondi R, Xia Y, Cardounel AJ, Druhan LJ, Ambrosio G, Zweier JL (2007) Myocardial ischemia results in tetrahydrobiopterin (BH4) oxidation with impaired endothelial function ameliorated by BH4. Proc Natl Acad Sci USA 104:15081-15086. doi:10.1073/pnas.0702986104

9. Gladwin MT, Shelhamer JH, Schechter AN, Pease-Fye ME, Waclawiw MA, Panza JA, Ognibene FP, Cannon RO 3rd (2000) Role of circulating nitrite and $S$-nitrosohemoglobin in the regulation of regional blood flow in humans. Proc Natl Acad Sci USA 97:11482-11487. doi:10.1073/pnas.97.21.11482

10. Gödecke A, Decking UK, Ding Z, Hirchenhain J, Bidmon HJ, Gödecke S, Schrader J (1998) Coronary hemodynamics in endothelial NO synthase knockout mice. Circ Res 82:186-194. doi:10.1161/01.RES.82.2.186

11. Heinzel FR, Gres P, Boengler K, Duschin A, Konietzka I, Rassaf T, Snedovskaya J, Meyer S, Skyschally A, Kelm M, Heusch G, Schulz R (2008) Inducible nitric oxide synthase expression and cardiomyocyte dysfunction during sustained moderate ischemia in pigs. Circ Res 103:1120-1127. doi:10.1161/CIRCRESAHA. 108.186015

12. Hendgen-Cotta U, Grau M, Rassaf T, Gharini P, Kelm M, Kleinbongard P (2008) Reductive gas-phase chemiluminescence and flow injection analysis for measurement of the nitric oxide pool in biological matrices. Methods Enzymol 441:295-315. doi:10.1016/S0076-6879(08)01216-0

13. Hendgen-Cotta UB, Kelm M, Rassaf T (2010) A highlight of myoglobin diversity: the nitrite reductase activity during myocardial ischemia-reperfusion. Nitric Oxide 22:75-82. doi:10. 1016/j.nox.2009.10.003

14. Hendgen-Cotta UB, Merx MW, Shiva S, Schmitz J, Becher S, Klare JP, Steinhoff HJ, Goedecke A, Schrader J, Gladwin MT, Kelm M, Rassaf T (2008) Nitrite reductase activity of myoglobin regulates respiration and cellular viability in myocardial ischemia-reperfusion injury. Proc Natl Acad Sci USA 105:10256-10261. doi:10.1073/pnas.0801336105

15. Heusch G, Post H, Michel MC, Kelm M, Schulz R (2000) Endogenous nitric oxide and myocardial adaptation to ischemia. Circ Res 87:146-152. doi:10.1161/01.RES.87.2.146

16. Horn P, Cortese-Krott MM, Keymel S, Kumara I, Burghoff S, Schrader J, Kelm M, Kleinbongard P (2011) Nitric oxide influences red blood cell velocity independently of changes in the vascular tone. Free Radic Res 45:653-661. doi:10.3109/ 10715762.2011.574288

17. Janssens S, Pokreisz P, Schoonjans L, Pellens M, Vermeersch P, Tjwa M, Jans P, Scherrer-Crosbie M, Picard MH, Szelid Z, Gillijns H, Van de Werf F, Collen D, Bloch KD (2004) Cardiomyocyte-specific overexpression of nitric oxide synthase 3 improves left ventricular performance and reduces compensatory hypertrophy after myocardial infarction. Circ Res 94:1256-1262. doi:10.1161/01.RES.0000126497.38281.23

18. Jax TW, Peters AJ, Plehn G, Schoebel FC (2009) Hemostatic risk factors in patients with coronary artery disease and type 2 diabetes-a two year follow-up of 243 patients. Cardiovasc Diabetol 8:48. doi:10.1186/1475-2840-8-48

19. Jax TW, Peters AJ, Plehn G, Schoebel FC (2009) Relevance of hemostatic risk factors on coronary morphology in patients with diabetes mellitus type 2. Cardiovasc Diabetol 8:24. doi:10.1186/ 1475-2840-8-24

20. Jones SP, Girod WG, Palazzo AJ, Granger DN, Grisham MB, Jourd'Heuil D, Huang PL, Lefer DJ (1999) Myocardial ischemiareperfusion injury is exacerbated in absence of endothelial cell nitric oxide synthase. Am J Physiol 276:H1567-H1573

21. Keymel S, Heiss C, Kleinbongard P, Kelm M, Lauer T (2011) Impaired red blood cell deformability in patients with coronary artery disease and diabetes mellitus. Horm Metab Res 43:760-765. doi:10.1055/s-0031-1286325 
22. Kleinbongard P, Dejam A, Lauer T, Jax T, Kerber S, Gharini P, Balzer J, Zotz RB, Scharf RE, Willers R, Schechter AN, Feelisch M, Kelm M (2006) Plasma nitrite concentrations reflect the degree of endothelial dysfunction in humans. Free Radic Biol Med 40:295-302. doi:10.1016/j.freeradbiomed.2005.08.025

23. Kleinbongard P, Dejam A, Lauer T, Rassaf T, Schindler A, Picker O, Scheeren T, Gödecke A, Schrader J, Schulz R, Heusch G, Schaub GA, Bryan NS, Feelisch M, Kelm M (2003) Plasma nitrite reflects constitutive nitric oxide synthase activity in mammals. Free Radic Biol Med 35:790-796. doi:10.1016/S08915849(03)00406-4

24. Kleinbongard P, Schulz R, Rassaf T, Lauer T, Dejam A, Jax T, Kumara I, Gharini P, Kabanova S, Ozüyaman B, Schnürch HG, Gödecke A, Weber AA, Robenek M, Robenek H, Bloch W, Rösen P, Kelm M (2006) Red blood cells express a functional endothelial nitric oxide synthase. Blood 107:2943-2951. doi:10. 1182/blood-2005-10-3992

25. Kobara M, Tatsumi T, Takeda M, Mano A, Yamanaka S, Shiraishi J, Keira N, Matoba S, Asayama J, Nakagawa M (2003) The dual effects of nitric oxide synthase inhibitors on ischemiareperfusion injury in rat hearts. Basic Res Cardiol 98:319-328. doi:10.1007/s00395-003-0423-x

26. Krusche CA, Holthöfer B, Hofe V, van de Sandt AM, Eshkind L, Bockamp E, Merx MW, Kant S, Windoffer R, Leube RE (2011) Desmoglein 2 mutant mice develop cardiac fibrosis and dilation. Basic Res Cardiol 106:617-633. doi:10.1007/s00395-011-0175-y

27. Langrehr JM, Murase N, Markus PM, Cai X, Neuhaus P, Schraut W, Simmons RL, Hoffman RA (1992) Nitric oxide production in host-versus-graft and graft-versus-host reactions in the rat. J Clin Invest 90:679-683. doi:10.1172/JCI115911

28. Li H, Samouilov A, Liu X, Zweier JL (2001) Characterization of the magnitude and kinetics of xanthine oxidase-catalyzed nitrite reduction. Evaluation of its role in nitric oxide generation in anoxic tissues. J Biol Chem 276:24482-24489. doi:10.1074/jbc. M011648200

29. Martin C, Schulz R, Post H, Boengler K, Kelm M, Kleinbongard P, Gres P, Skyschally A, Konietzka I, Heusch G (2007) Microdialysis-based analysis of interstitial NO in situ: NO synthaseindependent NO formation during myocardial ischemia. Cardiovasc Res 74:46-55. doi:10.1016/j.cardiores.2006.12.020

30. Martin C, Schulz R, Post H, Gres P, Heusch G (2003) Effect of NO synthase inhibition on myocardial metabolism during moderate ischemia. Am J Physiol Heart Circ Physiol 284:H2320H2324. doi:10.1152/ajpheart.01122.2002

31. Merx MW, Flögel U, Stumpe T, Gödecke A, Decking UK, Schrader J (2001) Myoglobin facilitates oxygen diffusion. FASEB J 15:1077-1079. doi:10.1096/fj.00-0497fje

32. Merx MW, Liehn EA, Graf J, van de Sandt A, Schaltenbrand M, Schrader J, Hanrath P, Weber C (2005) Statin treatment after onset of sepsis in a murine model improves survival. Circulation 112:117-124. doi:10.1161/CIRCULATIONAHA.104.502195

33. Merx MW, Liehn EA, Janssens U, Lütticken R, Schrader J, Hanrath P, Weber C (2004) HMG-CoA reductase inhibitor simvastatin profoundly improves survival in a murine model of sepsis. Circulation 109:2560-2565. doi:10.1161/01.CIR.0000129774.09737.5B

34. Minetti M, Agati L, Malorni W (2007) The microenvironment can shift erythrocytes from a friendly to a harmful behavior: pathogenetic implications for vascular diseases. Cardiovasc Res 75:21-28. doi:10.1016/j.cardiores.2007.03.007

35. Mohandas N, Chasis JA, Shohet SB (1983) The influence of membrane skeleton on red cell deformability, membrane material properties, and shape. Semin Hematol 20:225-242

36. Nossuli TO, Lakshminarayanan V, Baumgarten G, Taffet GE, Ballantyne CM, Michael LH, Entman ML (2000) A chronic mouse model of myocardial ischemia-reperfusion: essential in cytokine studies. Am J Physiol Heart Circ Physiol 278:H1049-H1055
37. Pepys MB, Baltz M, Gomer K, Davies AJ, Doenhoff M (1979) Serum amyloid P-component is an acute-phase reactant in the mouse. Nature 278:259-261. doi:10.1038/278259a0

38. Rassaf T, Bryan NS, Kelm M, Feelisch M (2002) Concomitant presence of $\mathrm{N}$-nitroso and S-nitroso proteins in human plasma. Free Radic Biol Med 33:1590-1596. doi:10.1016/S08915849(02)01183-8

39. Rassaf T, Bryan NS, Maloney RE, Specian V, Kelm M, Kalyanaraman B, Rodriguez J, Feelisch M (2003) NO adducts in mammalian red blood cells: too much or too little? Nat Med 9:481-482. doi:10.1038/nm0503-481

40. Rassaf T, Feelisch M, Kelm M (2004) Circulating NO pool: assessment of nitrite and nitroso species in blood and tissues. Free Radic Biol Med 36:413-422. doi:10.1016/j.freeradbiomed.2003.11.011

41. Rassaf T, Poll LW, Brouzos P, Lauer T, Totzeck M, Kleinbongard P, Gharini P, Andersen K, Schulz R, Heusch G, Mödder U, Kelm M (2006) Positive effects of nitric oxide on left ventricular function in humans. Eur Heart J 27:1699-1705. doi:10.1093/eur heartj/ehl096

42. Reiling N, Kröncke R, Ulmer AJ, Gerdes J, Flad HD, Hauschildt S (1996) Nitric oxide synthase: expression of the endothelial, Ca2+/ calmodulin-dependent isoform in human B and T lymphocytes. Eur J Immunol 26:511-516. doi:10.1002/eji.1830260302

43. Schulz R, Rassaf T, Massion PB, Kelm M, Balligand JL (2005) Recent advances in the understanding of the role of nitric oxide in cardiovascular homeostasis. Pharmacol Ther 108:225-256. doi:10.1016/j.pharmthera.2005.04.005

44. Szelid Z, Pokreisz P, Liu X, Vermeersch P, Marsboom G, Gillijns H, Pellens M, Verbeken E, Van de Werf F, Collen D, Janssens SP (2010) Cardioselective nitric oxide synthase 3 gene transfer protects against myocardial reperfusion injury. Basic Res Cardiol 105:169-179. doi:10.1007/s00395-009-0077-4

45. Totzeck M, Hendgen-Cotta UB, Luedike P, Berenbrink M, Klare JP, Steinhoff HJ, Semmler D, Shiva S, Williams D, Kipar A, Gladwin MT, Schrader J, Kelm M, Cossins AR, Rassaf T (2012) Nitrite regulates hypoxic vasodilation via myoglobin-dependent nitric oxide generation. Circulation 126:325-334. doi:10.1161/ CIRCULATIONAHA.111.087155

46. van de Sandt AM, Windler R, Gödecke A, Ohlig J, Zander S, Reinartz M, Graf J, van Faassen EE, Rassaf T, Schrader J, Kelm M, Merx MW (2013) Endothelial NOS (NOS3) impairs myocardial function in developing sepsis. Basic Res Cardiol 108:330. doi:10.1007/s00395-013-0330-8

47. Wood KC, Cortese-Krott MM, Kovacic JC, Noguchi A, Liu VB, Wang X, Raghavachari N, Boehm M, Kato GJ, Kelm M, Gladwin MT (2013) Circulating blood endothelial nitric oxide synthase contributes to the regulation of systemic blood pressure and nitrite homeostasis. Arterioscler Thromb Vasc Biol 33:1861-1871. doi:10.1161/ATVBAHA.112.301068

48. Yang BC, Nichols WW, Mehta JL (1996) Cardioprotective effects of red blood cells on ischemia and reperfusion injury in isolated rat heart: release of nitric oxide as a potential mechanism. J Cardiovasc Pharmacol Ther 1:297-306. doi:10.1177/ 107424849600100405

49. Yedgar S, Koshkaryev A, Barshtein G (2002) The red blood cell in vascular occlusion. Pathophysiol Haemost Thromb 32:263-268. doi:10.1159/000073578

50. Zanardo RC, Costa E, Ferreira HH, Antunes E, Martins AR, Murad F, De Nucci G (1997) Pharmacological and immunohistochemical evidence for a functional nitric oxide synthase system in rat peritoneal eosinophils. Proc Natl Acad Sci USA 94:14111-14114

51. Zhao X, He G, Chen YR, Pandian RP, Kuppusamy P, Zweier JL (2005) Endothelium-derived nitric oxide regulates postischemic myocardial oxygenation and oxygen consumption by modulation of mitochondrial electron transport. Circulation 111:2966-2972. doi:10.1161/CIRCULATIONAHA.104.527226 